\title{
Customer Systems Development
}

\section{Le développement des systèmes de clientèle}

\author{
par John Mowbray \\ Northumbrian Water
}

Les besoins et les attentes des consommateurs changent rapidement et pour survivre et développer leurs affaires, les sociétés doivent répondre au changement à la fois en adaptant leurs méthodes de gestion d'exploitation et les systèmes qui supportent cette exploitation. Northumbrian Water a pris le parti d'une grande flexibilité des systèmes. Trois ans auparavant, ICIS était utilisé pour la première fois pour la facturation des clients. Ensuite, les fonctions de services au consommateurs furent utilisés et les liens avec les autres services établis. L'avenir montre que nous avons besoin de garder différentes données sur différents secteurs et ensembles de clients et cela est partiellement achevé. Mais nous savons que leurs attentes vont encore changer et nous sommes prêts.

\section{CUSTOMER EXPECTATIONS}

In recent years we have seen an increase in the expectations of customers regarding their water and sewerage services. The level of expectation depends on where the company or the country is on the building blocks of expectations shown in figure 1 .

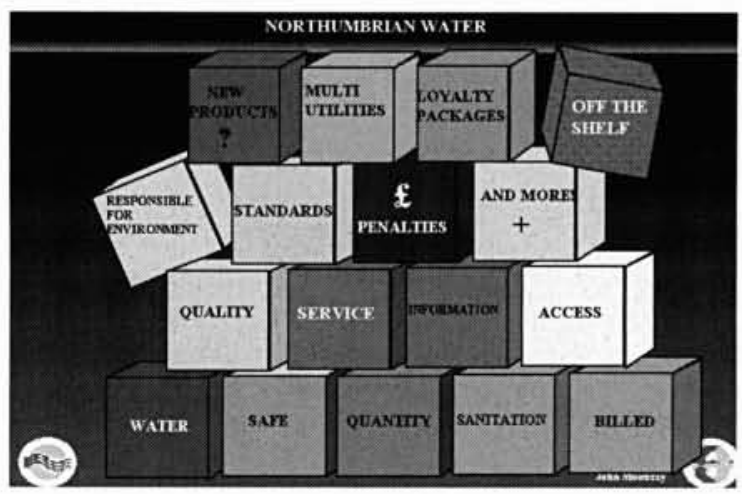

Figure 1- Building Blocks of Customer Expectations

This illustrates that in some parts of the world, the bottom or basic level of service starts with a supply of water, which should then be safe and there should be enough of it. Eventually, you must bill for that service and levels of expectation rise to the next level of blocks. Everyone must judge where sit on the chart, but in England, we are now probably situated at level 3 looking at more standards of service, compensation and other benefits for customers, but we are moving rapidly top level 4 and thereafter a level 5 will be added!

\section{WHY DEVELOP SYSTEMS ?}

The purpose of this chart is to show the development of systems to meet not only the needs of the business (and therefore the shareholder) but also the expectations and needs of customers and regulators. These external pressures particularly for quality customer service drove the business needs within Northumbrian Water. Traditionally, billing systems provided everything that you needed, but typically they would be inflexible and difficult to change i.e. you could meet the needs of level 1 but couldn't move to level 2 or beyond. This risk was reflected in the old technology that was used. Figure 2 below illustrates the point that a billing system can help on level 1 but does not have the flexibility to move upwards.

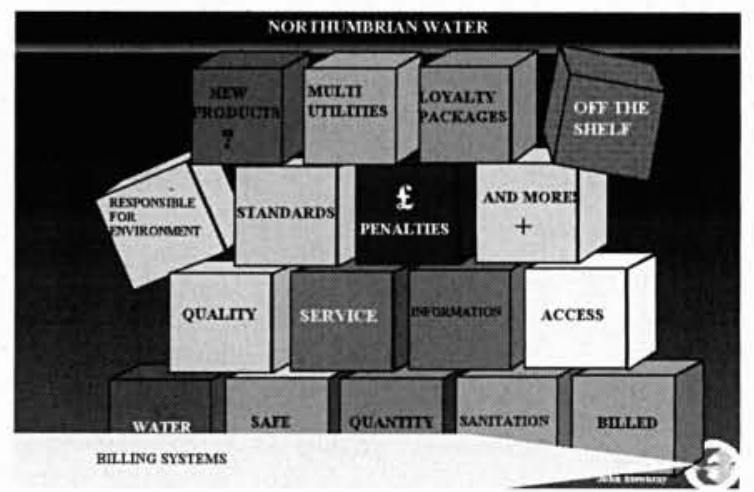

Figure 2 - The impact of billing systems. 


\section{MEETING BUSINESS NEEDS}

In Northumbrian Water, we identified how we wanted to meet future needs and reduce risk by developing an Information Technology platform for the 21 st century, i.e. to allow us to move to level 2 and 3 and beyond. That platform included the following :

- Client Server Environment,

— UNIX based platform,

- ORACLE,

- Mix of applications for business needs.

The development of the platform, however, was only a part of the future development needed. In July 1992, the design and development of ICIS (International Customer Information System) commenced. The aim of the partners at that time was to develop a customer information system for international use. The needs of Lyonnaise Des Eaux for an international system coincided with the needs of its English subsidiaries to move forward from a billing system and eliminate the risks of old technology. The project was developed by Northumbrian Water and Essex and Suffolk Water (the English Subsidiaries), Lyonnaise Des Eaux (DSI and Lyd Informatique) and CGI (now part of IBM).

The English Companies needed to move up the levels on the chart due to customer and regulatory pressure. The industry regulator, OFWAT (the Office of Water Services) introduced a number of guaranteed standards of services for customers and produced levels of service reports to show customers how companies were performing. These standards include penalties of $£ 10$ and upwards in the event of failure to perform, which make it critical to have proper systems in place or there is a consequence of significant penalties being paid. Figure 3 below illustrates the impact of ICIS

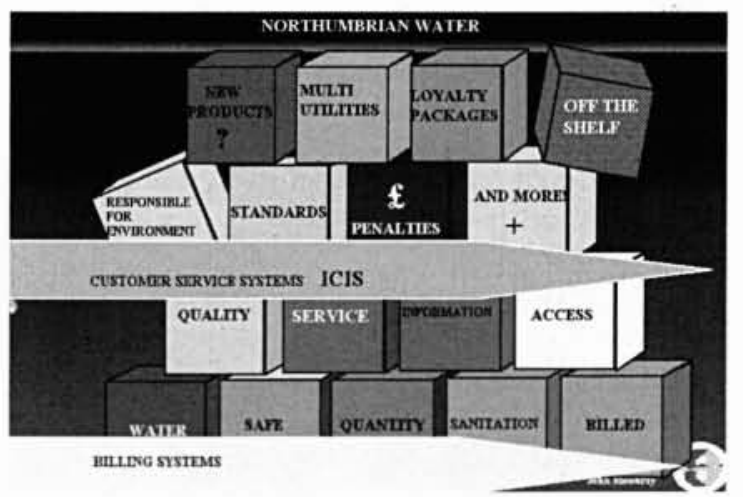

Figure 3 - The impact of ICIS

\section{IV — HISTORY OF ICIS}

ICIS was first used to bill over 300,000 customers in North East Water (now merged with Northumbrian Water) and a similar number in Essex and Suffolk Water in 1995/96. The Customer Service functions were introduced in 1996 and when Lyonnaise des Eaux took over Northumbrian Water and merged it with North East Water in the same year, it was able to transfer an additional 600,000 customers onto the system. Now the system is being introduced to other parts of the world including France, Hungary, South America and the Far East.

\section{V $\square$ WHAT IS ICIS ?}

ICIS was developed in modular form allowing use of all or part of the system e.g. you can use the billing part by itself (fulfilling the lower level need) or the customer service function or parts thereof. Data management within the system allows proper management of customers i.e. as they move from property to property. It also allows you to build your company structures within the system to allow the passage of information between different areas. Properties can be linked to customers and assets such as meters. System development does not have to happen at the centre ; indeed, whilst there is a core system which all users can use, local development is not only allowed but is also necessary to fully represent local needs. There is also a high level of parameterisation in terms of reference data and such as billing rules and debt recovery.

Figure 3 shows the impact of ICIS and its prime objective is customer satisfaction by enabling a rapid, efficient and quality response. There is access to data on-line, which is not only present day data but also, historical. For example it holds data which enables you to track back on customer contacts to identify the pattern/trend of such contacts.

The customer service functionality of ICIS allows you to monitor performance of agents against pre-set criteria, and includes the following :

- Contact - Issue - Action - Call Slip i.e. the resolution of a customer problem may be an instant response to the issue raised by the contact or you may need to generate some action by another agent to resolve it ;

- Diary facility for Appointments i.e. where action is needed an appointment can be made in the diary for the agent or team at the point of contact ;

- Bulletin Boards highlight issues which may impact on a large number of customers ;

- Information can also be stored and generated relating to interruptions and supply availability. ICIS can be used for cut off management i.e. notifying customers of cut off times.

A typical ICIS screen is shown on figure 4.

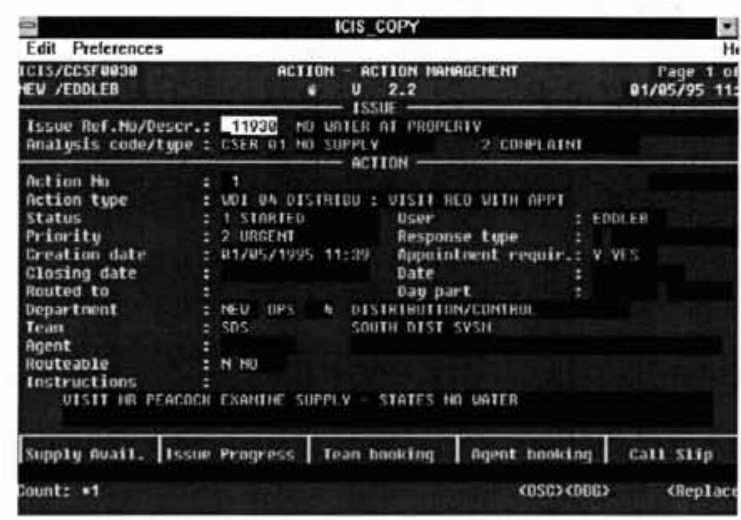

Figure 4 : A typical ICIS screen.

The billing functionality of ICIS allows you to carry out typical billing for measured and unmeasured accounts including the processing of payments and complex debt recovery procedures. The major change from traditional systems is the link to the customer rather than just to the property. 


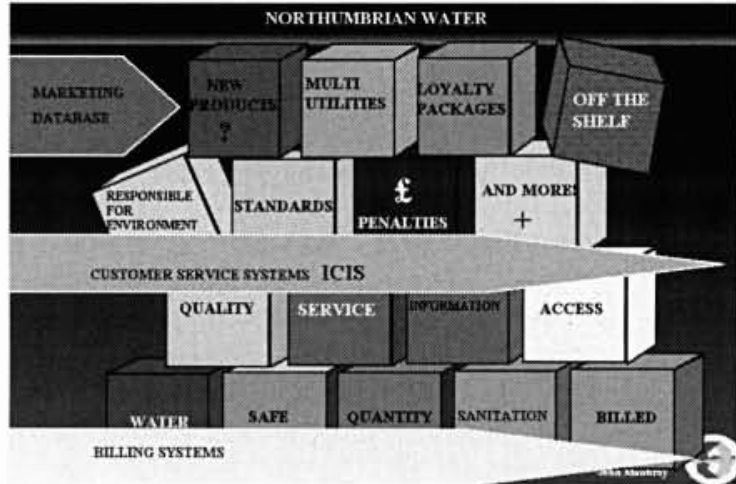

Figure 5- How the marketing database helps with higher level expectations.

\section{VI — INTEGRATION}

ICIS was developed as true international system, which could operate in large or small companies. Its flexibility allows it to be linked to other systems. Northumbrian Water did not want ICIS to stand in isolation against its own internally developed systems and successfully integrated ICIS with its GIS (Geographical Information System) and EnGarde (Asset/Works Management System). Central to this integration is a unique Property Reference Number (PRN) which ties data from ICIS to mapping information in GIS and works information in EnGarde. Two examples highlight how this can be used to the benefit of the business.

1. If a contact from a customer reveals a network problem, the link into GIS will reveal the location of such and immediately, the agent can identify which other properties will be affected. The links back to ICIS identify who should be contacted and such contact is recorded. EnGarde, meanwhile, has the details of the work carried out, including such as timing of the interruption. If details such as timing change, this can be carried out by the agent managing the work, but accessed by the agent dealing with the customers.

2 . Whilst the systems each have their own reporting mechanisms these can also be linked. For example, the complaint manager facility in GIS can collect data from ICIS on all contacts from customers by type and of course, location over variable periods of time. It can then display this information on a map of the entire region or by area. This allows the company to identify " hot spots" i.e. areas where particular problems seem to be occurring. One type of analysis might be complaints of discoloured water where the analysis will show whether an area is generally affected by it or whether it is just one street or even one or two houses.

\section{VII — FUTURE DEVELOPMENTS}

The building blocks of customer expectations show that amongst other things you cannot stand still as the demands of

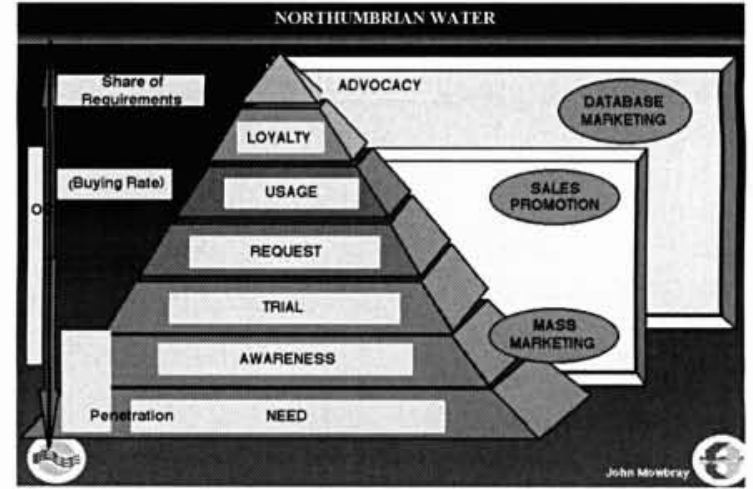

Figure 6 -A marketing view of systems development

customers generally change, but also the demands of different customers change disproportionately to others. In England, it is no longer acceptable, for example to provide similar levels of service to domestic and non-domestic customers - the latter expect much, much more and on the basis of how much they spend compared to the domestic customer, their demands are not unreasonable. Competition is being introduced into the industry, initially for large users of water. Price is a key element but service is also very important.

Northumbrian Water has extended its customer systems by adding a marketing database to enhance its current systems profile. Figure 5 below shows how this helps to meet higher level expectations.

This database analyses those non-domestic customers and allows segmentation of them according to their needs. Northumbrian, for example, has 65,000 customers classed as non-domestic, but 50,000 of these employ less than 10 people and the balance have different degrees of sensitivity to the product they receive - for some it is an essential part of their process, but for others it is for hygiene only purposes. Equally, for some it is a major part of their operating costs and a small change in price has a major impact on their business, whereas for others, the bill may be large but a small part of their overall costs. The marketing database concentrates effort on these customers where you need more information than the standard customer database. If you think of the customer base as a market rather than as a captive audience, Figure 5 illustrates the benefit of the marketing database as an add on to existing systems. Usually, our emphasis is mass marketing to everyone delivering the same high quality service, but to win loyalty and the advocacy, when our customers promote our product, we need to do more. This way we can retain our existing business as well as extend it by winning more business.

As the need to segment our market more increases so our approach to systems development will change. What we do for industrial and commercial customers today, we will need to do for domestic customers tomorrow. Perhaps this is where level 5 on the building blocks sit ! 